\title{
Access Pricing to a Digital Broadcasting Platform
}

\author{
Germà Bel, Joan Calzada, and Raquel Insa \\ Department of Economic Policy \\ University of Barcelona, Spain
}

\begin{abstract}
This article studies a television market where operators can sell access to programs and to advertising time. First, we determine the retail prices paid by viewers and advertisers to a monopoly platform when there are externalities between these two markets. We compare the prices that an unregulated platform would establish with the welfare maximizing prices. Second, we obtain the access charge that an independent programmer should pay to a television platform for using one of his channels. We show that the optimal access charge takes into account the direct cost of access and the platform's opportunity costs in the viewer and advertiser markets, which are affected by the externalities between the two markets.
\end{abstract}

In recent years, some countries such as France, Italy, and Spain have witnessed a considerable concentration in the satellite and cable television markets that affects the viability of independent programmers. ${ }^{1}$ Television platforms try to control the production of content because they consider the selection of programs to be essential to attract consumers. Although technological progress has considerably increased the operator's transmission capacity, the demand for pay-per-view television has not increased in the same proportion. As a result, the demand is frequently served by those platforms that are able to broadcast mass events, such as football matches.

In the television industry, broadcasting activity has a cost structure with important elements of natural monopoly that make difficult the introduction of competition. By contrast, the production of programs has economic characteristics that make this activ-

Correspondence should be addressed to Joan Calzada, Department of Economic Policy, University of Barcelona, Av. Diagonal 690, Barcelona 08034, Spain. E-mail: calzada@ub.edu

${ }^{1}$ Concentration of ownership in the media industry was studied by Chan-Olmsted and Litman (1988), Chan-Olmsted (1996), and Wildman, (1998). The works of Albarran and Dimmick (1996) and Peltier (2004) contain empirical studies on this issue. Parsons (2003) offered a review of horizontal integration in the cable television industry. 
ity prone to competition. Therefore, policies intended to promote independent television programmers (IPs) have potential welfare enhancing effects. Taking this into account, in the last years the growing concentration of the broadcasting activity has driven the television authorities to facilitate the access of IPs to the monopolistic platforms. In Spain, for example, in 2003 the television regulator approved a merger between the two satellite platforms that were serving the Spanish market. The regulator made this decision because she believed that two competitive satellite services could not survive financially. ${ }^{2}$ Nonetheless, they imposed conditions on the merger intended to preserve a degree of competition. Specifically, they mandated that a number of channels be set aside to be leased to firms not owned by the platform.

A similar situation appears in the United States. In this case, cable operators are also required to set aside a number of leased access channels to be used by independent network providers who pay an access fee to use them. The Cable Act of 1984 and subsequent rulings by the Federal Communications Commission (FCC) established the number of channels that each cable operator is required to make available for leased access and the rates that can be charged. The FCC considered that leased access would provide a check on anticompetitive behavior and would become an established channel acquisition mechanism. ${ }^{3}$ Despite this, leased access programmers complain about the many difficulties that they have to face. ${ }^{4}$ In this situation, an adequate access regulation is essential to introduce competition in a concentrated television market. If the access charge is too high, it prevents the entry of independent programmers, and if it is too low, it endangers the financial stability of the television platform. Having this in mind, the goal of this article is to determine pricing principles that should be used to guarantee the access to a monopoly platform.

We consider a model where a television platform and a group of IPs are financed through the prices charged to viewers and advertisers. We assume that the firms know the demand for programs and for ad time. Taking this into account, they choose the per-minute price of these services to maximize the profit at the

\footnotetext{
${ }^{2}$ Caffarra and Coscelli (2003) explained that antitrust authorities consider the financial consolidation of the sector as inevitable and try to control the process by imposing conditions on mergers. Some recent studies show that the concentration processes in the audiovisual market do not necessarily diminish welfare (Anderson \& Coate, 2005), and that concentration can bring benefits, such as an increase in the product variety offered (Berry \& Waldfogel, 2001). Other papers have challenged this result. Cunningham and Alexander (2004) showed that concentration would reduce per-viewer advertising prices and decrease welfare. Goolsbee and Petrin (2004) indicated that a concentration process in a particular platform (i.e., cable television) can be compatible with the existence of effective competition from other platforms (i.e., satellite broadcasting). On the other hand, Mullainathan and Shleifer (2005) showed that competition among news providers does not eliminate media bias. The determinant of accuracy is not competition per se but consumer heterogeneity.

${ }^{3}$ The FCC even envisioned channel brokers, who would accumulate leased channels and sublease them in groups. See a more detailed explanation in Federal Communications Commission (1990).

${ }^{4}$ See, for instance, introductory remarks on the Website of Leased Access Programmers Association (LAPA), www.leasedaccess.org
} 
same time that they satisfy the constraint imposed by the broadcasting capacity of each channel. In this context, we determine the retail prices that viewers and advertisers have to pay when there is a unique television programmer. Afterwards, we also consider the case where a group of IPs enter the market and lease one channel of the platform to broadcast its own content.

The first contribution of this article is to determine the price paid by viewers and advertisers when there are externalities between the two types of consumers. In our model, we assume that viewers have a greater disutility the more advertisements are inserted in the scheduling and that advertisers obtain a higher utility with larger audiences. ${ }^{5}$ To analyze the effect of these externalities on retail prices, we first study the case of an unregulated monopoly platform that only commercializes one channel. We show that the viewer's price should be corrected downwards to reflect the positive externality that their participation creates on the advertisers. Moreover, the advertiser's price should be corrected upward to reflect the negative externality that advertisements generate on viewers. On the other hand, we explain that the prices of an unregulated platform do not incorporate the full impact of the externalities because the platform does not take into account the utility of viewers and advertisers. By contrast, the optimal regulation considers the consumer's utility and brings about a reduction of prices.

Our approach in this article is related to the research on two-sided markets. This literature studies the strategic behavior of a platform that serves different types of consumers of which at least one creates externalities for the others. If there are externalities, the consumer's surplus of the members of one market depends on the number of users of the other market. This occurs, for example, in the Yellow Pages $^{6}$ (connects potential buyers and sellers), newspapers ${ }^{7}$ (connect readers and advertisers), credit card companies (act as intermediaries between vendors and consumers), and television platforms (that allow advertisers to reach audiences). ${ }^{8}$

\footnotetext{
${ }^{5}$ Cunningham and Alexander (2004) were the first to explore advertising elasticities in the television market, taking into account the switching-off behavior of viewers in response to increased advertising. In contrast to Anderson and Coate (2005), they predicted that an increase in concentration leads broadcasters to increase advertising shares. The increase in commercial time, relative to the volume of content, drives away viewers and raises the subscription fee that subscribers pay and the per-viewer advertising price to advertisers. On the other hand, Brown and Alexander (2005) presented an empirical paper that shows that markets with greater concentration charge more for advertising and attract more viewers.

${ }^{6}$ See Rysman (2004) for an approximation to this type of market.

${ }^{7}$ Corden (1952) is the first paper that analyzes the relationship between newspapers' advertising and reader markets.

${ }^{8}$ According to Evans (2003), in these cases the presence of such a platform generates an increase of welfare when: (a) there are different groups of consumers, (b) the members of a group benefit from having their demand coordinated with one or more members of another group, (c) an intermediary can facilitate this coordination more efficiently than can bilateral relations between the members of the group. Dewenter (2003) offered a detailed review of the theoretical and empirical literature that analyzes this problem in the mass media.
} 
The two-sided market approach can be traced back to Rosse (1979), who presented an empirical analysis of the interdependence of newspapers' subscribers and advertisers. ${ }^{9}$ Later on, Blair and Romano (1993) provided a formal analysis of a newspaper monopolist who sells advertising space in the newspaper as well as the newspaper itself. They show the complexity of determining the prices, because the demand for advertising space rises with increases in circulation and the circulation demand rises with increases in the quantity of advertising. In the television market, Owen and Wildman (1992) characterized the behavior of viewers and advertisers and provide a graphical treatment of their interaction. Owen and Wildman (1992) explained that when

the programmer sells advertising time and charges viewers, the subscription charge will be lower than the price would be if the program were supported by viewer payments only, and less commercial time will be sold than would be the case if the channel were entirely ad supported. (p. 129)

More recently, works by Anderson and Coate (2005), Armstrong (2006), Evans (2003), and Rochet and Tirole (2003) made important theoretical and empirical contributions to the two-sided market literature.

An important feature of platforms is that they can modify the prices for different groups within the market in accord with the magnitude of the network externalities generated on each side. In our model, the television platform considers the externalities between markets and charges a higher price to advertisers because they generate negative externalities on viewers. The platform sets prices reflecting the preferences of each group of consumers and the externalities that are present among the different groups.

The literature on two-sided markets has been especially important in the analysis of media sectors. Anderson and Coate (2005) developed a model where television channels compete to attract viewers and advertisers. Each channel has a monopoly over the advertisements that the viewers can watch. One result of this work is that competition for pay-per-view viewers generates fewer advertisements than what is optimal because channels reduce the number of advertisements to increase the number of viewers. With free to air channels, the result is more ambiguous. If viewers have a strong disutility with advertisements, the number of advertisements is higher than optimal. If their disutility is low, however, there will be fewer advertisements than desirable.

\footnotetext{
${ }^{9}$ Rosse (1979) explained that "the interdependence of the newspapers firm's two markets-advertising and subscriptions - is the source of what is sometimes called the 'infamous downward spiral.' It is this effect that makes being the 'junior paper' (smaller circulation paper) in a two paper market precarious. This is also the effect which sometimes accounts for the demise of newspaper competition among quite large newspapers even when differences in circulation are apparently small” (p. 456).
} 
Peitz and Valletti (2004) conducted a study where the content of the television channels is endogenous. They show that free to air channels produce similar content, whereas pay-per-view channels differentiate their programs. On the other hand, the authors explain that welfare does not necessary increase if the channels offer free to air television instead of pay-per-view to avoid the externalities between viewers and advertisers.

In contrast to these papers, we develop a model where product differentiation is exogenously fixed and where the channels can be financed simultaneously by the prices paid by viewers and advertisers, a situation that is in accord with the present reality of the Spanish television market. ${ }^{10}$ On the other hand, we assume that viewers and advertisers only contract for one channel of the platform and that channels compete to attract the two groups of consumers. ${ }^{11} \mathrm{~A}$ consequence of these assumptions is that the prices established for each type of consumer depend on the externalities created for the other type.

The second contribution of this article is to determine the optimal access charge that IPs should pay to the television platform to use one of its channels. ${ }^{12}$ The access problem that we are examining is similar to the interconnection problem in the telecommunication sector that was analyzed by Baumol (1983), Baumol and Sidak (1994), Laffont and Tirole (1994, 1996), Armstrong, Doyle, and Vickers (1996), Wildman (1997), and Armstrong and Vickers (1998), among others. ${ }^{13}$ This literature examined the optimal price that should be established to access a part of a network that is monopolized by an operator. The objective is to introduce competition in the retail market, while maintaining the monopoly of the essential facility. In this article, we consider a model where a platform operates two differentiated television channels and leases one of them to a competitive fringe of IPs. We show that the optimal capacity charge depends on the direct cost of broadcasting the channel

\footnotetext{
${ }^{10}$ According to Peitz and Valletti (2004), pay-per-view Canal+ in Spain is $7 \%$ financed by advertisements. On the other hand, there are several IPs such as Media Park, Buzz and Natura that are partly financed with advertisements.

${ }^{11}$ Peitz and Valleti (2004) assumed that announcers can reach all consumers.

${ }^{12}$ In this article, we don't analyze the possibility where the incumbent is interested in offering access to his rivals. Sappington and Unel (2005) explained that industry producers can employ privately-negotiated input prices to exploit consumers. The input buyer may agree to pay a high price for an input because the high prices serve to reduce the intensity of the retail price competition. However, retail price regulation, multiple potential entrants, and retail product heterogeneity can limit the extent to which privately-negotiated input prices can be used to disadvantage consumers. The authors also showed that when the incumbent has lower downstream costs than the entrant the firms will not conduct input price negotiations.

${ }^{13}$ Complete reviews on access charges in telecommunications can be found in Laffont and Tirole (2000), Armstrong (2002), and Vogelsang (2003). Many insights of this literature can be directly applied to other sectors such as gas, rail or postal services, where the access problem is also very important. Indeed, compulsory access to essential facilities is one of the central features of recent regulatory policy in many network industries, as pointed out by Kearney and Merrill (1998) and Spulber and Yoo (2003).
} 
and on the platform's opportunity cost of giving access to the IPs. The platform's opportunity cost reflects how its profit in the viewer and advertiser markets is reduced when there is entry.

An important difference of our article with respect to the literature on access charges is that the platform's opportunity cost takes into account the externalities between the two markets. On the other hand, instead of considering a per-minute access charge we assume that the IPs demand a fixed amount of broadcast capacity on the platform. ${ }^{14}$ One advantage of this access system is that IPs can freely use the capacity purchased. Thus, for example, they can broadcast more advertisements and fewer programs than the platform. Finally, an additional contribution of our article is that it connects the literatures on access charges in network industries and on two-sided markets. To our knowledge, no article has studied the access problem in the television market before.

The rest of the article continues as follows: First we discuss the merger between two Spanish digital satellite broadcasters in 2003. After that, we present the main features of our model. In the following section we determine the retail prices of a unique television platform that offers programs to viewers and broadcasts advertisements for a group of firms. We identify the effect on prices of the externalities between these two groups of consumers. Moreover, we compare the prices of an unregulated and a regulated platform. Next, we examine the case of a television platform that operates two channels and leases one to a group of IPs. We determine the optimal capacity charge that the IPs must pay to the platform for the leased channel. Finally, the last section summarizes and discusses our main results.

\section{THE MERGER OF THE SATELLITE PLATFORMS IN SPAIN}

Spain has a small and competitive pay-per-view market. ${ }^{15}$ In 2004, the penetration of the television service was $88.9 \%$ of the total population, and 32.9 million persons watched the television every day. In spite of this, less than 3.5 million persons subscribed to a pay-per-view television channel. In November 2003, the Spanish authorities approved the merger of the only two Spanish satellite television platforms, Sogecable and Via Digital, which became Digital+. The authorization of this merger was based on the need to guarantee the viability of the firms. Sogecable

\footnotetext{
${ }^{14}$ See Calzada (2003) for a more detailed analysis of this type of access.

${ }^{15}$ In Spain the pay-per-per view channels and platforms compete with many free-on-air televisions. Moreover, there are several pay-per-view platforms that use different broadcasting technologies: Digital+ (satellite), MTV (satellite), cable operators, Imagenio (TV on ADSL), and digital terrestrial television operators. In addition, there is an important number of independent programmers such as Expansion TV, Canal Barça, Factoría de Ficción, Canal Cosmopolitan, Eurosport News, Planeta 2010, Meda Park, Buzz, Natura, Odisea, Club Super 3, and so forth.
} 
had 1,878,074 subscribers in 2003 and Via Digital 662,664, whereas in 2004 the number of subscribers of the new operator Digital+ fell to 2,093,817 subscribers. Moreover, in this period the revenues in the satellite market increased from 1,376,6 millions euros to 1,418 millions. ${ }^{16}$

On the other hand, it is important to explain that in Spain the presence of the cable operators is relatively small. Although 50\% of the Spanish homes have access to the cable operators, in 2004 there were only 1,124,049 subscribers to cable and cable operators only generated 274.9 million euros in revenues. Therefore, in the pay-per-view market $83.8 \%$ of all revenues are generated by Digital+. This prominence of the satellite television in Spain contrasts with the situation in other European countries, but this situation is not surprising if we take into account the process of liberalization of the telecommunications sector in Spain. Indeed, while the two satellite platforms were launched in 1997 and bought the rights to broadcast sport events and premium programs very quickly, the cable operators initiated their emissions after 2000 and have had many problems building up their networks and obtaining attractive programs.

It is still early to confirm whether Digital+ has fulfilled all the expectations created before its launch. After the merger the satellite market has fewer viewers but generates more revenue. Moreover, the merger has allowed a reduction in broadcasting costs. In Spain there are two satellites available and after the merger they compete to broadcast the content of Digital+. ${ }^{17}$

The Spanish Government established several conditions before approving the merger. One was the establishment of a PRI-X that will control the retail prices of Digital+ until 2008. ${ }^{18}$ Another important condition was that Digital+ has to dedicate a part of its broadcast capacity to wholesale digital services. Digital+ must incorporate in its platform 20 independent channels that can compete directly with its programs. This regulation allows the IPs to commercialize simultaneously their programs through the cable operators and Digital+, although Digital+ has more subscribers. Despite this obligation, initially the government did not regulate the access charges that IPs have to pay to Digital+. ${ }^{19}$ In this situation, some operators negotiate access charges with Digital+. However, some well-established IPs decided to

\footnotetext{
${ }^{16}$ See Spanish Telecommunications Regulatory Agency (2003, 2005).

${ }^{17}$ In fact, after the merger was approved, Digital+ renegotiated agreements with Astra and Hispasat satellites to broadcast its programming.

${ }^{18}$ The PRI-X is a price cap mechanism that controls the evolution of the price of one service, or the weighted average price of a basket of services. This price cap requires that a regulated firm update its prices according to the Retail Price Index (RPI) minus a factor X that reflects the productivity of the industry. When the factor $\mathrm{X}$ is higher than the RPI, this implies that at the end of the regulatory period the regulated firm must reduce its prices. In Spain, in 2003 the government established a PRI-2 over Digital+.

${ }^{19}$ It was just required that wholesale services should be offered in fair, transparent conditions and that the access charges should be cost oriented. In practice, the bargaining process with the IPs must include factors such as the costs of the satellite spot, equipment amortization, and an adjustment based on fee per subscriber.
} 
stay out of the market, and other IPs such as EHS.tv (a home shopping channel) requested the intervention of the Spanish Telecommunications Regulatory Agency (CMT) to establish the access charge. On January 2004, CMT finally proposed to use cost-oriented access charges to facilitate the entry of some IPs using Digital+. The CMT established different charges for free-to-air and for pay-per-view operators. The access charges reflect the cost differences of serving these two types of firms. However, the proposal of the CMT does not take into account that the entrants in the satellite television market can capture a part of the platform's viewers and force a change in its pricing strategy. The commercial strategy of new operators may have large or small effects on the budget equilibrium of the platform.

\section{THE MODEL}

This section presents a model of a platform that commercializes television channels to viewers and advertisers. To simplify the analysis, we assume that the platform only offers two channels, $i=1,2$, that are differentiated à la Hotelling. Each channel consists of a single stream of programs and advertisements such that only one of them can be watched at a time. The daily transmission capacity of each channel is restricted to $K_{i}$, where $K_{l}=K_{2} \cdot{ }^{20}$ This is the maximum number of minutes of television programs and ad time that can be broadcast during 1 day through Channel $i$. For simplicity, we also assume that viewers and advertisers only contract for one channel. Therefore, we do not reproduce the usual practice of television platforms of commercializing different bundles of channels to attract specific groups of consumers.

The television platform knows the viewers' demand curve, $Q\left(p_{\mathrm{i}}\right)$, and the advertisers' demand curve, $X\left(s_{\mathrm{i}}\right)$, for each Channel $i$. Having this in mind, it computes an implicit per-minute price for the programs $p_{\mathrm{i}}$ and a price for the ad time $s_{\mathrm{i}}$, and determines the number of minutes of programs and ad time to maximize its profits. We make the simplifying assumption that the demands for programs and for ad time are so large that at the equilibrium prices the capacity constraint of the two channels is binding and there are no portions of the day in which capacity is unused.

Once the per-minute price of programs has been determined the platform sets a fee equal to $p_{\mathrm{i}} Q_{\mathrm{i}}$, which allows viewers to watch $Q_{\mathrm{i}}$ minutes of programming free of advertisements. The viewers consider this fee and decide if they contract to the platform or if they stay out of the market. We assume that the viewers' net surplus from consuming $Q_{\mathrm{i}}$ minutes of programming is $v\left(p_{\mathrm{i}}\right)$, where $\partial v\left(p_{i}\right) / \partial p_{i}=-Q\left(p_{i}\right)$.

\footnotetext{
${ }^{20}$ In the case of a cable platform, the capacity depends on the number of circuits of optical fiber installed. In a satellite platform, the capacity depends on the terms of the agreement with the satellite operator.
} 
The potential viewers of the platform consist of a population that is distributed uniformly with density one on the space $[0,1]$. This span represents the preferences of the viewers for television services. We consider that Channel 1 is located at $O$ and Channel 2 is located at 1 . On the other hand, the utility of the viewers also depends on their location and on the dissatisfaction produced to them by the advertisements inserted in the programs. Taking this into account, one subscriber of Channel $i$ located distance $V$ from the channel's position obtains the payoff:

$$
v\left(p_{i}\right)-\alpha_{1} A_{i} X\left(s_{i}\right)-V t_{1},
$$

where $t_{1}$ is the transport cost and $V t_{1}$ is the cost of going from $V$ to the channel. To reflect the negative externality that advertisements cause on viewers, we consider that $A_{i}$ is the number of firms that broadcast their advertisements in Channel $i$, and that each firm contracts $X\left(s_{\mathrm{i}}\right)$ units of ad time, where $\partial X\left(s_{i}\right) / \partial s_{i}<0$. Finally, $\alpha_{1}$ shows the relative importance of the externalities originated by the advertisements.

We assume that the viewer's utility is high enough as to guarantee that all of them contract for one channel. In this case, given the prices of the programs and the ad time, the market share of viewers obtained by each channel is determined as in Hotelling's model. A consumer located distance $V$ from channel's 1 position and distance $(1-V)$ from channel's 2 position will be indifferent between the two channels when:

$$
v\left(p_{1}\right)-\alpha_{1} A_{1} X\left(s_{i}\right)-V t_{1}=v\left(p_{2}\right)-\alpha_{1} A_{2} X\left(s_{2}\right)-(1-V) t_{1} .
$$

From this expression, assuming that viewers are distributed uniformly in the space $[0,1]$, we obtain the number of consumers of Channel 1 :

$$
V_{1}=\frac{1}{2}+\frac{v\left(p_{1}\right)-v\left(p_{2}\right)+\alpha_{1} X_{2}\left(1-A_{1}\left(\frac{X_{2}+X_{1}}{X_{2}}\right)\right)}{2 t_{1}},
$$

where $X_{\mathrm{i}}=X\left(s_{\mathrm{i}}\right)$, and assuming that advertisers are distributed uniformly with density one on the segment $[0,1]$, we have $A_{2}=\left(1-A_{1}\right)$. Because each viewer only contracts for one channel, $V_{1}$ is the marginal consumer that separates the viewers of the two channels. Moreover, the number of viewers of Channel 2 is simply $V_{2}=\left(1-V_{1}\right)$.

The population of advertisers consists of a group of firms that are interested in inserting their advertisements in the programs of the channels. To simplify, we assume that advertisers are monopolists of their own products and that the advertisements allow them to increase demand. ${ }^{21}$ Advertisers' locations reflect their preferences for the channels. Each channel is situated in one extreme of the unit segment and offers content more or less related with the products of the advertisers.

\footnotetext{
${ }^{21}$ Dukes and Gal-Or (2003) modeled how the preferences of the firms for the advertisements are originated.
} 
Each firm broadcasts $X\left(s_{\mathrm{i}}\right)$ minutes of ad time and pays the platform a per-minute price $s_{\mathrm{i}}$. The advertiser's net surplus for broadcasting advertisements is defined as $w\left(s_{\mathrm{i}}\right)$, where $\partial w\left(s_{i}\right) / \partial s_{i}=-X\left(s_{i}\right)$. In addition, we consider that the utility of the advertisers also depends on the type of programs that are broadcast and on the number of viewers of the channels. The advertisers want the maximum diffusion for their products, and therefore, they obtain more utility when the audience of the platform is big. We assume that the audience for the two channels remains constant during the day to preclude the possibility of price discrimination. ${ }^{22}$ Taking this into account, one advertiser of Channel $i$ located distance $A$ from the channel's location has the pay-off:

$$
w\left(s_{i}\right)+\alpha_{2} V_{i}-A t_{2},
$$

where we consider that advertisers have a cost $A t_{2}$ of going from $A$ to the channel. On the other hand, the positive externality that viewers generate on the firms is represented by $\alpha_{2} V_{i}$, where the parameter $\alpha_{2}$ is the weight of the externality.

Imagine that the utility that firms obtain with the advertisements is so high that all of them participate in the market. A firm located at $A$ will be indifferent between the two channels when

$$
w\left(s_{1}\right)+\alpha_{2} V_{1}-A t_{2}=w\left(s_{2}\right)+\alpha_{2} V_{2}-(1-A) t_{2} .
$$

If we now define $V_{2}=\left(1-V_{1}\right)$, we can express the number of firms that broadcast their advertisements over Channel 1 as follows:

$$
A_{1}=\frac{1}{2}+\frac{w\left(s_{1}\right)-w\left(s_{2}\right)+\alpha_{2}\left(2 V_{1}-1\right)}{2 t_{2}} .
$$

Consequently, when the two channels have the same audience $\left(V_{1}=V_{2}\right)$, the one that charges a lower price obtains a larger share of the market. On the other hand, if the two channels have the same audience and establish the same price they share the market in equal parts.

Finally, imagine that the platform has a marginal cost $c_{1}$ to produce and broadcast its programs and $b_{1}$ to broadcast advertisements. We call $B$ the cost of operating one unit of capacity of Channel $i$, where we define one unit of capacity as one unit of broadcasting time (e.g., $1 \mathrm{hr}$ ). Finally, we consider that the platform has a fixed cost $F$.

Taking into account this model, in the next section we analyze how the platform determines the implicit per-minute prices of programs and the prices for ad time when there exist externalities between viewers and advertisers. In this situation, we present a simplified version of the model where the platform only operates one channel and there is no entry. This simple case allows identifying the complexities

\footnotetext{
${ }^{22}$ Brown and Cavazos (2005) conducted an empirical study that shows that advertisers prefer the programming content that best "frames" their advertising. As a result, some programs receive a premium, while others receive a discount.
} 
of regulating the retail prices in a two-sided television market. Afterwards, in the following section we consider the model where the platform manages two channels and a fringe of independent programmers leases the platform's Channel 2 to broadcast their content. Our objective is to determine the optimal condition for the capacity charge.

\section{The Retail Prices of a Monopoly Platform}

This section examines the prices that a monopoly television platform charges to viewers and advertisers when it only operates Channel 1 . First, we determine the prices established by an unregulated platform and afterwards we compare the results with the prices that would be set by a regulator that maximizes welfare.

Following Equation 1, when there is partial participation in the market a viewer $V$ decides to buy television programs only if $v\left(p_{i}\right)-V t_{1}-\alpha_{1} A_{1} X_{1} \geq 0$. The viewer $V_{1}$ that satisfies this equation with equality is the marginal viewer that separates the consumers that contract for programs and those that stay out of the market. It is straightforward to verify that the channel's number of viewers is reduced by the implicit per-minute price of the programs, the number of advertisers, and the transportation cost. On the other hand, following Equation 4, when there is partial participation a firm $A$ invests in publicity only when $w\left(s_{1}\right)-A t_{2}+\alpha_{2} V_{1} \geq 0$. Once we know the advertiser $A_{1}$ that satisfies this expression with equality we can determine the number of advertisers on the platform. The number of advertisers is reduced by the price of the ad time and the transportation cost, and it is increased by the audience of the platform.

We assume that the platform only sells programs and ad time through Channel 1. In particular, it maximizes the following profit function:

$$
\pi_{1}\left(p_{1}, s_{1}, K_{1}\right)=\left(V_{1} p_{1}-c_{1}\right) Q\left(p_{1}\right)+A_{1}\left(s_{1}-b_{1}\right) X\left(s_{1}\right)-\beta K_{1}-F,
$$

subject to the capacity constraint $Q\left(p_{1}\right)+A_{1} X\left(s_{1}\right) \leq K_{1}$.

Define $\mu \geq 0$ as the multiplier associated with the platform's capacity constraint, and write $Q_{1}=Q\left(p_{1}\right)$ and $X_{1}=X\left(s_{1}\right)$. The next proposition shows the price for the programs and ad time that would establish an unregulated platform (all proofs are in the Appendix).

Proposition 1. The price-cost margins for each minute of programs and ad time broadcast on an unregulated monopoly satisfy:

$$
\frac{p_{1}-\frac{c_{1}+\beta}{V_{1}}}{p_{1}}=\frac{1}{\varepsilon_{p_{1}}}-\frac{t_{2} p_{1} Q_{1}}{\varepsilon_{p_{1}} V_{1}\left(t_{1} t_{2}+\alpha_{1} \alpha_{2} X_{1}\right)}-\frac{\alpha_{2}\left(s_{1}-b_{1}-\beta\right)}{\varepsilon_{p_{1}} V_{1}\left(t_{1} t_{2}+\alpha_{1} \alpha_{2} X_{1}\right)},
$$




$$
\begin{aligned}
& \frac{s_{1}-\left(b_{1}+\beta\right)}{s_{1}}=\frac{1}{\varepsilon_{s_{1}}}-\left(\frac{1}{\varepsilon_{s}}-\frac{\alpha_{1} \alpha_{2} A_{1}}{s_{1} t_{1}}\right) \frac{t_{1}\left(s_{1}-b_{1}-\beta\right) X_{1}}{A_{1}\left(t_{1} t_{2}+\alpha_{1} \alpha_{2} X_{1}\right)}+ \\
& \left(\frac{1}{\varepsilon_{s_{1}}}+\frac{V_{1} \alpha_{2}+w\left(s_{1}\right)}{s_{1} X_{1}}\right) \frac{X_{1} \alpha_{1} p_{1} Q_{1}}{A_{1}\left(t_{1} t_{2}+\alpha_{1} \alpha_{2} X_{1}\right)},
\end{aligned}
$$

where $\varepsilon_{p}$ and $\varepsilon_{s}$ are the price elasticities for each service.

These conditions show how the conventional price-cost margins of a monopoly should be modified when there are externalities between viewers and advertisers. The per-minute price charged to viewers, $p_{1}$, is adjusted downward to increase their participation (second term in the RHS of Equation 8) and to reflect the positive externality that viewers generate on advertisers (third term on the RHS). The increase in audience increases the willingness to pay of advertisers and this generates a further benefit to the platform. Observe that if the last two terms of Equation 8 are big enough the price of programs is negative, which implies that viewers should receive compensation to watch programs.

The price-cost margin of ad time is also adjusted by two factors. First, the price is reduced to raise the participation of firms (second term in the RHS of Equation 9). In spite of this, it could be efficient to increase (instead of reduce) the price of ad time because a reduction in the number of advertisements increases the participation of viewers. The solution depends on the relative size of the two terms in brackets.

Second, the price of ad time is adjusted upwards reflecting the positive externality that a reduction in the number of advertisements generates on viewers (third term in the RHS of Equation 9). An increase in the price of ad time increases the number of viewers for two reasons: there are fewer advertisers and each one broadcasts fewer advertisements.

Adjustments in the prices to viewers and advertisers caused by the externalities imply that advertisers subsidize viewers through the price of ad time. The magnitude of the subsidy depends on the importance of the externalities, which are reflected by the parameters $\alpha_{1}$ and $\alpha_{2}$. Interestingly, this situation could explain why some television platforms broadcast their programs free to air and are financed exclusively through advertising. Actually, Armstrong (2006) explicitly showed this result in his more general analysis of unregulated platforms.

Next, we examine the Ramsey retail prices that a regulator would establish to maximize welfare. The Ramsey prices are those that maximize social welfare subject to the firm's break-even constraint. Therefore, with these prices the regulator is not seeking Pareto improvements to the unregulated equilibrium. The welfare function that the regulator considers is the unweighted sum of the viewers' and advertisers' surpluses and the profits of the television platform:

$$
\begin{aligned}
& W\left(p_{1}, s_{1}, K_{1}\right)=V_{1}\left[v\left(p_{1}\right)-\alpha_{1} A_{1} X_{1}-\bar{V} t_{1}\right]+ \\
& A_{1}\left[w\left(s_{1}\right)+\alpha_{2} V_{1}-\bar{A} t_{2}\right]+\pi_{1}\left(p_{1}, s_{1}\right),
\end{aligned}
$$


subject to the break-even and capacity constraints:

$$
\begin{gathered}
\pi_{1} \geq 0 \\
\mathrm{Q}\left(p_{1}\right)+A_{1} X\left(s_{1}\right) \leq K_{1},
\end{gathered}
$$

where $\bar{V}$ and $\bar{A}$ reflect the average distance between the viewer's and advertiser's position and Channel 1 . Define $\lambda \geq 0$ as the multiplier associated with the platform's budget constraint and $\mu \geq 0$ as the multiplier associated with the platform's capacity restriction. On the other hand, $\pi_{1}\left(p_{1}, s_{1}, K_{1}\right) \geq 0$ is the same profit function as the one defined in Equation 7.

Proposition 2. The price-cost margins for each minute of programs and ad time that a welfare maximizing regulator establishes satisfy:

$$
\begin{aligned}
& \frac{p_{1}-\frac{c_{1}+\beta}{V_{1}}}{p_{1}}=\frac{\theta}{\varepsilon_{p_{1}}}-\frac{t_{2}\left[p_{1} Q_{1}+\delta_{1}\right]}{\varepsilon_{p_{1}} V_{1}\left(t_{1} t_{2}+\alpha_{1} \alpha_{2} X_{1}\right)}-\frac{\alpha_{2}\left[\left(s_{1}-b_{1}-\beta\right)+\delta_{2}\right]}{\varepsilon_{p_{1}} V_{1}\left(t_{1} t_{2}+\alpha_{1} \alpha_{2} X_{1}\right)}, \\
& \frac{s_{1}-\left(b_{1}+\beta\right)}{s_{1}}=\frac{\theta}{\varepsilon_{s_{1}}}-\left(\frac{1}{\varepsilon_{s}}-\frac{\alpha_{1} \alpha_{2} A_{1}}{s_{1} t_{1}}\right) \frac{t_{1}\left[\left(s_{1}-b_{1}-\beta\right) X_{1}+\delta_{3}\right]}{A_{1}\left(t_{1} t_{2}+\alpha_{1} \alpha_{2} X_{1}\right)}+ \\
& \left(\frac{1}{\varepsilon_{s_{1}}}+\frac{V_{1} \alpha_{2}+w\left(s_{1}\right)}{s_{1} X_{1}}\right) \frac{X_{1} \alpha_{1}\left[p_{1} Q_{1}+\delta_{4}\right]}{A_{1}\left(t_{1} t_{2}+\alpha_{1} \alpha_{2} X_{1}\right)}+\frac{\alpha_{1} V_{1}}{1+\lambda},
\end{aligned}
$$

where $\theta=\lambda /(1+\lambda)$.

The optimal price-cost margins are similar to those of Proposition 1. However, we can identify two important differences. First, under rather general conditions, as $\theta<1$ the optimal prices are lower than those of the monopoly. Second, the optimal retail prices that maximize welfare take into account the effect of the externalities on the utility of viewers and advertisers. These externalities are reflected by the terms $\delta_{1}, \delta_{2}, \delta_{3}$, and $\delta_{4}$, which do not appear in the prices of an unregulated platform (a formal definition of these terms can be found in the appendix). The term $\delta_{1}$ shows the change in the utility of viewers and advertisers when an increase in the price of programs reduces the platform's number of viewers. Similarly, $\delta_{3}$ reflects the change in these utilities when the reduction in the number of viewers is caused by a change in the price of ad time. On the other hand, the term $\delta_{2}$ reflects the change in the utility of viewers and advertisers when an increase in the price of programs reduces the platform's number of advertisers. Similarly, the term $\delta_{4}$ shows the change in these utilities when the reduction in the number of advertisers is caused by the price of ad time. Finally, the last term in Equation 12 shows the negative externality that advertisements produce on the utility of viewers. An in- 
crease in the price of the ad time reduces the number of advertisements and increases the utility of viewers.

To sum up, as with conventional Ramsey prices, the platform's retail prices are directly related with the production cost and indirectly related with the elasticity of the demand of the services. ${ }^{23}$ Moreover, the retail prices are adjusted to take into account the externalities between the markets.

Finally, note that the price of ad time could be interpreted as an access charge that advertisers pay to the platform for using its broadcasting capacity. The formula for the optimal price of ad time is simpler than the traditional rules for access charges, but this is due to the fact that the television programs and the advertisements are independent services. In spite of this, note that each minute of ad time sold by the platform represents one less minute of programs that it can commercialize. Having this in mind, the platform offers broadcasting space to advertisers while its opportunity cost is lower than the price of ad time.

\section{The Regulation of Access to a Television Platform}

The objective of this section is to analyze the regulation of the capacity charge that IPs have to pay when they lease one channel of a monopoly television platform. Consider the general model of the previous section when a platform operates two channels and assume that a group of IPs leases the platform's Channel 2 to broadcast $q_{2}$ minutes of programs and $x_{2}$ minutes of ad time. We assume that each channel can only broadcast one program at a time. Therefore, we consider that only one independent programmer offers all programs of Channel 2, or that there are different IPs that queue up to create a schedule that fills the channel. To avoid the possibility of vertical separation between the retail and wholesale activities, we assume that IPs can only use Channel 2. Moreover, IPs are unable to bypass the platform: that is, they can not create their own platform or buy broadcasting capacity from another platform.

We call $c_{2}$ and $b_{2}$ the IPs' marginal costs of acquiring and broadcasting programs and broadcasting ad time. On the other hand, when IPs access Channel 2 they pay to the platform a capacity charge, $a$, for each unit of broadcasting capacity. ${ }^{24}$ This capacity can be used to broadcast different combinations of programs and ad time, which can have different qualities than those that the platform would provide. The daily broadcasting capacity of Channel 2 that IPs lease from the platform is $\hat{K}_{2}(a) \leq K_{2}$.

We assume that the competitive fringe of entrants behaves as if it were a single price-taking firm. Therefore, we consider the case of one IP that maximizes profits

\footnotetext{
${ }^{23}$ Some comparative statics can be conducted applying the implicit function theorem, but the complexity of the results makes their economic interpretation difficult.

${ }^{24}$ It will be straightforward to consider the case where the IP contracts the two channels. Indeed, this would imply the vertical separation between wholesale activities and the broadcast of programs.
} 
taking as given the price of the programs, $p_{2}^{2}$, the price of the ad time, $s_{2}^{2}$, and the access charge $a$.

$$
\pi_{2}(a) \equiv \max _{\left\{q_{2} \geq 0, x_{2} \geq 0\right\}}:\left(V_{2} p_{2}^{2}-c_{2}\right) q_{2}+A_{2}\left(s_{2}^{2}-b_{2}\right) x_{2}-a K_{2},
$$

subject to the capacity constraint: $q_{2}+A_{2} x_{2} \leq K_{2}$, where $V_{2}$ and $A_{2}$ are the numbers of viewers and advertisers served by the IP. Note that when the IP enters the market, the access charge and the equilibrium prices of the two channels, $\left(\hat{p}_{1} \hat{s}_{1}\right)$ and $\left(\hat{p}_{2}^{2}, \hat{s}_{2}^{2}\right)$, equate the broadcasting capacity bought by the IP and the minutes of programming and advertising time it supplies. Having this in mind, the IP's demand for capacity is:

$$
q_{2}\left(\hat{p}_{2}^{2}, a\right)+A_{2} x_{2}\left(\hat{s}_{2}^{2}, a\right)=\hat{K}_{2}(a) .
$$

The television platform has three sources of revenue: payments from viewers and advertisers and access revenues from the IP. It maximizes the following profit function:

$$
\begin{aligned}
& \pi_{1}\left(p_{1}, p_{2}, s_{1}, s_{2}, a\right)= \\
& \sum_{j=1}^{2}\left[\left(V_{j} p_{j}-c_{1}\right) Q_{j}+A_{j}\left(s_{j}-b_{1}\right) X_{j}-\beta K_{j}\right]+a \hat{K}_{2}(a)-F,
\end{aligned}
$$

subject to the capacity constraints:

$$
\begin{aligned}
& Q_{1}+A_{1} X_{1} \leq K_{1} \\
& Q_{2}+A_{2} X_{2}+\hat{K}_{2}(a) \leq K_{2} .
\end{aligned}
$$

where $Q_{\mathrm{j}}=Q\left(p_{\mathrm{j}}\right)$ and $X_{\mathrm{j}}=X\left(s_{\mathrm{j}}\right)$ are the minutes of programs and ad time broadcast by the platform on Channel $j$. Note that if the IP leases Channel 2, $Q_{2}=0$ and $X_{2}=$ 0 , and $\hat{K}_{2}=q_{2}+A_{2} x_{2}>0$. Thus, the platform only broadcasts content through Channel 1.

Finally, consider a regulator that determines the platform's retail prices and the capacity charge for Channel 2 to maximize social welfare. The regulator's welfare function is the unweighted sum of the viewers' and advertisers' surpluses and the profits of the television platform and the IP. The regulator maximizes the welfare function

$$
\begin{aligned}
& W\left(p_{j}, s_{j}, a\right)=\sum_{j=1}^{2}\left[\begin{array}{l}
V_{j}\left(v\left(p_{j}\right)-\alpha_{1} A_{j} X_{j}-\bar{V}_{j} t_{1}\right)+ \\
A_{j}\left(w\left(s_{j}\right)+\alpha_{2} V_{j}-\bar{A}_{j} t_{2}\right)
\end{array}\right]+ \\
& \pi_{1}\left(p_{j}, s_{j}, a\right)+\pi_{2}\left(p_{2}^{2}, s_{2}^{2}, a\right)
\end{aligned}
$$

subject to the break-even and capacity constraints: 


$$
\begin{aligned}
& \pi_{1} \geq 0 \\
& Q_{1}+A_{1} X_{1} \leq K_{1} \\
& Q_{2}+A_{2} X_{2}+\hat{K}_{2}(a) \leq K_{2} .
\end{aligned}
$$

This problem can be represented by the following Lagrangian:

$$
\begin{aligned}
& L\left(p_{j}, s_{j}, a\right)=\sum_{j=1}^{2}\left[\begin{array}{l}
V_{j}\left(v\left(p_{j}\right)-\alpha A_{j} X_{j}-\bar{V}_{j} t_{1}\right)+ \\
A_{j}\left(w\left(s_{j}\right)+\alpha_{2} V_{j}-\bar{A}_{j} t_{2}\right)
\end{array}\right]+ \\
& (1+\lambda) \pi_{1}\left(p_{j}, s_{j}, a\right)+\pi_{2}\left(p_{2}, s_{2}, a\right)-\mu_{1}\left(Q_{1}+A_{1} X_{1}-K_{1}\right)- \\
& \mu_{2}\left[Q_{2}+A_{2} X_{2}+\hat{K}_{2}(a)-K_{2}\right],
\end{aligned}
$$

where $\mu_{i} \geq 0$ is the multiplier associated to the capacity constraint of Channel $i=$ 1,2 and $\lambda \geq 0$ is the multiplier of the platform's break-even constraint, $\pi_{1} \geq 0$.

The following proposition describes the optimal policy to facilitate the access to the platform's Channel 2.25

Proposition 3. Assume that $\lambda>0$ and the retail prices are higher than the first best. When the IP leases Channel 2, the optimal charge for each unit of capacity of Channel 2 satisfies:

$$
\begin{aligned}
& a=\beta+\frac{\theta a}{\varepsilon_{a}}+\left(V_{2} p_{2}-c_{1}-\beta\right) \sigma_{Q}+A_{2}\left(s_{2}-b_{1}-\beta\right) \sigma_{X}- \\
& \sum_{j=1}^{2} \psi_{j}\left[p_{j} Q_{j}+\frac{v\left(p_{j}\right)-\left(M_{j}+A_{j} B_{j}\right)}{1+\lambda}\right]- \\
& \sum_{j=1}^{2} \gamma_{j}\left[\left(s_{j}-b_{j}-\beta\right) X_{j}+\frac{w\left(s_{j}\right)-\left(N_{j}+V_{j} B_{j}\right)}{1+\lambda}\right]
\end{aligned}
$$

where $\sigma_{Q}=\frac{-\partial Q_{2}}{\partial_{a}} / \frac{\partial \hat{K}_{2}}{\partial_{a}}, \sigma_{X}=\frac{-\partial X_{2}}{\partial_{a}} / \frac{\partial \hat{K}_{2}}{\partial_{a}}, \psi_{j}=\frac{-\partial V_{j}}{\partial_{a}} / \frac{\partial \hat{K}_{2}}{\partial_{a}} \gamma_{j}=\frac{-\partial A_{j}}{\partial_{a}} / \frac{\partial \hat{K}_{2}}{\partial_{a}}$ and $\varepsilon_{a}=\frac{-\partial \hat{K}_{2}}{\partial_{a}} \frac{a}{\hat{K}_{2}(a)}$.

When the IP leases Channel 2 it should pay a capacity charge for each unit of capacity that is equal to the per unit cost of the capacity, $\beta$, plus the opportunity

\footnotetext{
${ }^{25}$ For simplicity, we do not present the conditions for the optimal retail prices, but an intuition about their structure could be obtained from the first order conditions in the Appendix.
} 
cost of the television platform when it offers broadcasting capacity to the IP and a positive Ramsey term that reflects the contribution of the capacity charge to the fixed costs. Interestingly, this tariffs' structure is similar to the per-minute access charge obtained by Laffont and Tirole (1994) and Armstrong et al. (1996) in their analyses of the one-way interconnection problem in the telecommunications sector, and to the capacity charge found by Calzada (2003) in a study of capacity-based access systems. In spite of this, the platform's opportunity cost of Equation 18 is more complex than in these papers, due to the presence of externalities between viewers and advertisers.

The last four terms in Equation 18 reflects the platform's opportunity cost in the viewers' and the advertisers' market. The expressions $\left(V_{2} p_{2}-c_{2}-\beta\right) \sigma_{Q}$ and $A_{2}\left(s_{2}-\right.$ $b-\beta) \sigma_{X}$ show the revenues lost by the platform in each market when it provides one unit of capacity of Channel 2 to the IP. The terms $\sigma_{Q}$ and $\sigma_{X}$ are analogous to the displacement ratio described by Armstrong et al. (1996), and measure the minutes of programs and advertisements that the platform stops broadcasting in each unit of capacity of Channel 2 when it lease one unit of capacity to the IP, due to a change in the capacity charge. Indeed, when the platform supplies Channel 2 to the IP, it losses the revenues that it previously obtained through the programs and ad time. Taking into account that the platform must break-even, the capacity charge must compensate the platform for the revenues lost.

The last two terms in Equation 18 are the modifications in the number of minutes of programs and ad time that entry produces in the two channels. If one IP leases Channel 2, it can change the retail prices of the channel, which in turn can modify the number of minutes of programs and advertising broadcast by the platform through Channel 1. For example, a change in the price charged to viewers of Channel 2 affects the number of viewers over the two channels. In addition, the externalities between viewers and advertisers also modify the number of minutes of the two services broadcasted across the two channels. ${ }^{26}$

To summarize, the optimal capacity charge takes into account the reduction in the platform's revenues caused by entry. The platform uses the revenues generated by the programs and ad time in the two channels to finance its fixed costs. When entry reduces these revenues, the capacity charge must help the platform to break-even. On the other hand, notice that the capacity charge depends on the commercial policy followed by the operators. The optimal charge is different when the revenues of the operators come from both viewers and advertisers, or when they are only generated by one of these sources. For example, if the firms do not insert advertisements in their programs, there are no externalities between the markets

\footnotetext{
${ }^{26}$ When the two channels of the platform can be leased by the IPs, in a symmetric equilibrium the market shares of the two channels become $V_{1}=V_{2}=1 / 2$ and $A_{1}=A_{2}=1 / 2$. In this situation, the equations about the optimal retail prices and the capacity charge can be substantially simplified because the externalities between markets are compensated.
} 
and the capacity charge rule is simpler. A different case would appear if only the IP broadcasts advertisements. If the disutility created by advertisements is important this would increase the number of viewers of the platform's channel and would reduce the opportunity cost of entry.

\section{CONCLUSION}

The growing tendency to concentration in the television sector makes the regulation of access to broadcasting platforms an essential instrument to promote competition. This article has analyzed the optimal capacity charge that independent providers should pay to a television platform when they access one channel. It has been shown that to correctly regulate the access charges it is necessary to take into account the externalities between viewers and advertisers.

The first contribution of the article is to determine the optimal retail prices for a television platform when there are externalities between viewers and advertisers. When viewers dislike advertisements they might accept an increase in ad time if the prices of the programs are reduced. In the advertisement's market we find the opposite case. Advertisers are willing to pay higher prices to broadcast their advertisements to larger audiences. Taking this situation into account, it is optimal to correct downward the per-minute price paid by the viewers to reflect the negative externalities created by the advertisements and to modify upwards the price of the ad time to reflect the positive externalities that advertisers obtain with large audiences.

The second contribution of this work is the identification of the optimal capacity charge that an IP should pay to a monopoly television platform to use its broadcast capacity. We show that the optimal capacity charge is equal to the direct cost of access, plus the platform's opportunity cost of giving access to the IP and a Ramsey term. More precisely, the platform's opportunity cost reflects the reduction of revenues that entry produces for the platform. First, the platform losses the revenues generated by the viewers and advertisers that contract the IP. Second, if the IP establishes different prices than the platform in the leased channel, there is a modification in the number of minutes dedicated to programs and advertisements in both channels.

The capacity charge paid by the IP should contribute to financing the fixed costs of the platform. However, the particular form that the capacity charge takes depends on the commercial policy of the IP and the platform. Our analysis shows that the optimal capacity charge is different when the IP broadcasts free to air and inserts advertisements in its programs than when it charges a price to viewers. Each situation causes a different damage to the platform and should be regulated differently. 


\section{ACKNOWLEDGMENTS}

This research has enjoyed financial support from Universidad Complutense de Madrid, the Spanish Association of Electronics, Information Technologies and Telecommunications Firms (AETIC), and from the Spanish Ministry of Science and Technology (BEC2003-01679). Germà Bel also acknowledges financial support from the Fundación Rafael del Pino.

This article was written while Germà Bel was Visiting Professor in Cornell Institute for Public Affairs at Cornell Univesity, and Joan Calzada was visiting the Tanaka Business School at Imperial College. Hospitality of both centers is gratefully acknowledged. We are thankful for comments from participants at the International Complutense Seminar on the Economics of Information and Communication (Madrid, 2004) and in a seminar at the Research Unit on Public Policies and Economic Regulation (PPRE-University of Barcelona). Very useful comments and suggestions were received from three anonymous referees and the editor.

\section{REFERENCES}

Albarran, A. B., \& Dimmick, J. (1996). Concentration and economies of multiformity in the communication industries. Journal of Media Economics, 9(4), 41-50.

Anderson, S. P., \& Coate, S. (2005). Market provision of broadcasting: A welfare analysis. Review of Economic Studies, 72, 947-972.

Armstrong, M. (2006). Competition in two-sided markets. Rand Journal of Economics, forthcoming.

Armstrong, M. (2002). The theory of access pricing and interconnection. In M. Cave, S. Majumdar, \& I. Vogelsang (Eds.), Handbook of telecommunications economics (Vol. 1, pp. 295-384). London: Elsevier Science.

Armstrong, M., Doyle, C., \& Vickers, J. (1996). The access pricing problem: A synthesis. The Journal of Industrial Economics, 44, 131-150.

Armstrong, M., \& Vickers, J. (1998). The access pricing problem with deregulation: A note. The Journal of Industrial Economics, 46, 115-121.

Baumol, W. J. (1983). Some subtle issues in railroad deregulation. International Journal of Transport Economics, 10(1-2), 341-355.

Baumol, W. J., \& Sidak, J. G. (1994). The pricing of inputs sold to competitors. Yale Journal of Regulation, 11, 171-202.

Berry, S. T., \& Waldfogel, J. (2001). Do mergers increase product variety? Evidence from radio broadcasting. Quarterly Journal of Economics, 116, 1009-1025.

Blair, R. D., \& Romano, R.E. (1993) Pricing decisions of the newspaper monopolist. Southern Economic Journal, 49, 721-32.

Brown, K., \& Alexander, P. J. (2005). Market structure, viewer welfare, and advertising rates in local broadcast television markets. Economic Letters, 86, 331-337.

Brown, K., \& Cavazos, R. (2005). Why is this show so dumb? Advertising revenue and program content of network television. Review of Industrial Organization, 27(1), 17-34.

Caffarra, C., \& Coscelli, A. (2003). Merger to monopoly: Newscorp/telepiú. European Competition Law Review, 24, 625-627. 
Calzada, J. (2003). Access by capacity and peak-load pricing. In Documents de Treball de la Facultat de Ciencies Economiques. Col.lecciod'Economia E03/108. Barcelona, Spain: Universitat de Barcelona.

Chan-Olmsted, S. M. (1996). Market competition for cable television: Reexamining its horizontal mergers and industry concentration. Journal of Media Economics, 9(2), 25-41.

Chan-Olmsted, S. M., \& Litman, B. R. (1988). Antitrust and horizontal mergers in the cable industry. Journal of Media Economics, 1(2), 3-28.

Corden, W. M. (1952). The maximisation profit by a newspaper. Review of Economic Studies, 20, 181-190.

Cunningham, B. M., \& Alexander, P. J. (2004). A theory of broadcast media concentration and commercial advertising. Journal of Public Theory, 6, 557-575.

Dewenter, R. (2003, June). The economics of media markets (Discussion Paper 10). Hamburg, Germany: Universität der Bundeswehr Hamburg.

Dukes, A., \& Gal-Or, E. (2003) Minimum differentiation in commercial media markets. Journal of Economics and Management Strategy, 12, 291-325.

Evans, D. (2003). The antitrust economics of multi-sided platform markets. Yale Journal on Regulation, 20, 352-382.

Federal Communications Commission. (1990, July 31). Competition, Rates Regulation, and the Commission's Policies Relating to the Provision of Cable Television Services (No. 90-276). Washington, DC: Federal Communications Commission.

Goolsbee, A., \& Petrin, A. (2004). The consumer gains from direct broadcast satellites and the competition with cable TV. Econometrica, 72, 351-381.

Kearney, J. D., \& Merrill, T. W. (1998). The great transformation of regulated industries law. Columbia Law Review, 98, 1323-1409.

Laffont, J. -J., \& Tirole, J. (1994). Access pricing and competition. European Economic Review, 38, $1673-1710$.

Laffont, J. -J., \& Tirole, J. (1996). Creating competition through interconnection: Theory and practice. Journal of Regulatory Economics, 10, 227-256.

Laffont, J. -J., \& Tirole, J. (2000). Competition in telecommunications. Cambridge, MA: The MIT Press.

Mullainathan, S., \& Shleifer, A. (2005). The market for news. American Economic Review, 95, 1031-1053.

Owen, B. M., \& Wildman, S. S. (1992). Video Economics. Cambridge, MA: Harvard University Press.

Parsons, P. R. (2003). Horizontal integration in the cable television industry: History and context. Journal of Media Economics, 16, 23-40.

Peitz, M., \& Valletti, T. M. (2004). Content and advertising in the media: Pay-TV versus free-to-air. CPRE Discussion Papers 4771. London: Centre for Economic Policy Research.

Peltier, S. (2004). Merger and acquisitions in the media industries: Were failures really unforeseeable? Journal of Media Economics, 17, 261-278.

Rochet, J. -C., \& Tirole, M. (2003). Platform competition in two-sided markets. Journal of the European Economic Association, 1, 990-1029.

Rosse, J. N. (1979). The evolution of one newspaper cities. Proceedings of the Symposium on Media Concentration (Vol. II, pp. 429-471). Washington, DC: Federal Trade Commission.

Rysman, M. (2004). Competition between networks: A study of the market for yellow pages. Review of Economic Studies, 71, 483-512.

Sappington, D., \& Unel, B. (2005) Privately-negotiated input prices. Journal of Regulatory Economics, 27, 263-280.

Spanish Telecommunications Regulatory Agency. (2003). Informe anual. Madrid, Spain: Comisión del Mercado de las Telecomunicaciones.

Spanish Telecommunications Regulatory Agency. (2005). Informe anual. Madrid, Spain: Comisión del Mercado de las Telecomunicaciones. 
Spulber, D. F., \& Yoo, C. S. (2003). Access to networks: Economic and constitutional connections. Cornell Law Review, 88, 885-1024.

Vogelsang, I. (2003). Price regulation of access to telecommunications networks. Journal of Economic Literature, 41, 830-862.

Wildman, S. S. (1997). Interconnection pricing, stranded costs, and the optimal regulatory contract. Industrial and Corporate Change, 6, 741-755.

Wildman, S. S. (1998). Media and multimedia. The challenge for policy and economic analysis. Information Economics and Policy, 10, 1-7.

\section{APPENDIX}

\section{Proof of Proposition 1}

The market shares for each service are:

$$
\begin{aligned}
& V_{1}\left(p_{1}, s_{1}\right)=\frac{t_{2} v\left(p_{1}\right)-\alpha_{1} w\left(s_{1}\right) X\left(s_{1}\right)}{t_{1} t_{2}+\alpha_{1} \alpha_{2} X\left(s_{1}\right)} \\
& A_{1}\left(p_{1}, s_{1}\right)=\frac{t_{1} w\left(s_{1}\right)+\alpha_{2} v\left(p_{1}\right)}{t_{1} t_{2}+\alpha_{1} \alpha_{2} X\left(s_{1}\right)}
\end{aligned}
$$

Differentiating the Lagrangian we obtain the following first order conditions for the prices and the capacity:

$$
\begin{gathered}
\left(V_{1} p_{1}-c_{1}\right) \frac{\partial Q_{1}}{\partial p_{1}}+V_{1} Q_{1}+\frac{\partial V_{1}}{\partial p_{1}} p_{1} Q_{1}+ \\
\frac{\partial A_{1}}{\partial p_{1}}\left[\left(s_{1}-b_{1}\right) X_{1}-\mu\left(\frac{\partial Q_{1}}{\partial p_{1}}+\frac{\partial A_{1}}{\partial p_{1}} X_{1}\right)\right]=0 \\
A_{1}\left(s_{1}-b_{1}\right) \frac{\partial X_{1}}{\partial s_{1}}+A_{1} X_{1}+\frac{\partial A_{1}}{\partial s_{1}}\left(s_{1}-b_{1}\right) X_{1}+ \\
\frac{\partial V_{1}}{\partial s_{1}} p_{1} Q_{1}-\mu\left(\frac{\partial A_{1}}{\partial s_{1}} X_{1}+A_{1} \frac{\partial X_{1}}{\partial s_{1}}\right)=0 \\
\mu \geq 0 ; \quad \mu\left(K_{1}-Q_{1}-A_{1} X_{1}\right)=0 \\
K_{1} \geq 0 ; \quad K_{1}(\mu-\beta)=0 .
\end{gathered}
$$


Finally, using $\varepsilon_{p_{1}}=\frac{-\partial Q_{1}}{\partial p_{1}} \frac{p_{1}}{Q_{1}}, \varepsilon_{s_{1}}=\frac{-\partial X_{1}}{\partial s_{1}} \frac{s_{1}}{X_{1}}$ and the market shares in Equations 19 we obtain the prices of the statement.

\section{Proof of Proposition 2}

Define $B=\alpha_{1} X_{\mathrm{i}}-\alpha_{2}$. After rearranging, the first order conditions that characterize the optimal retail prices and capacity are:

$$
\begin{aligned}
& \left(V_{1} p_{1}-c_{1}-\frac{\mu}{1+\lambda}\right) \frac{\partial Q_{1}}{\partial p_{1}}+\frac{\partial V_{1}}{\partial p_{1}}\left[p_{1} Q_{1}+\frac{v\left(p_{1}\right)-t_{1}\left(\bar{V}+V_{1} \frac{\partial \bar{V} / \partial p_{1}}{\partial V_{1} / \partial p_{1}}\right)-A_{1} B}{1+\lambda}\right]+ \\
& \frac{\partial A_{1}}{\partial p_{1}}\left[\left(s_{1}-b_{1}-\frac{\mu}{1+\lambda}\right) X_{1}+\frac{w\left(s_{1}\right)-t_{2}\left(\bar{A}+A_{1} \frac{\partial \bar{A} / \partial p_{1}}{\partial A_{1} / \partial p_{1}}\right)-V_{1} B}{1+\lambda}\right]=-\theta V_{1} Q_{1} \\
& A_{1}\left(s_{1}-b_{1}-\frac{\mu}{1+\lambda}\right) \frac{\partial X_{1}}{\partial s_{1}}+\frac{\partial V_{1}}{\partial s_{1}}\left[p_{1} Q_{1}+\frac{v\left(p_{1}\right)-t_{1}\left(\bar{V}+V_{1} \frac{\partial \bar{V} / \partial s_{1}}{\partial V_{1} / \partial s_{1}}\right)-A_{1} B}{1+\lambda}\right]+ \\
& \frac{\partial A_{1}}{\partial s_{1}}\left[\left(s_{1}-b_{1}-\frac{\mu}{1+\lambda}\right) X_{1}+\frac{w\left(s_{1}\right)-t_{2}\left(\bar{A}+A_{1} \frac{\partial \bar{A} / \partial s_{1}}{\partial A_{1} / \partial s_{1}}\right)-V_{1} B}{1+\lambda}\right]= \\
& \frac{V_{1} \alpha_{1} A_{1} \frac{\partial X_{1}}{\partial s_{1}}}{1+\lambda}-\theta X_{1}
\end{aligned}
$$

$$
\begin{gathered}
\mu \geq 0 ; \quad \mu\left(K_{1}-Q_{1}-A_{1} X_{1}\right)=0, \\
K_{1} \geq 0 ; \quad K_{1}(\mu-(1+\lambda) \beta)=0,
\end{gathered}
$$




$$
\lambda \geq 0 ; \quad \lambda \pi_{1}=0 .
$$

Define:

$$
\begin{aligned}
& \delta_{1}=\left(v\left(p_{1}\right)-t_{1}\left(\bar{V}+V_{1} \frac{\partial \bar{V} / \partial p_{1}}{\partial V_{1} / \partial p_{1}}\right)-A_{1} B\right) /(1+\lambda), \\
& \delta_{2}=\left(w\left(s_{1}\right)-V_{1} B-t_{2}\left(\bar{A}+A_{1} \frac{\partial \bar{A} / \partial p_{1}}{\partial A_{1} / \partial p_{1}}\right)\right) /(1+\lambda), \\
& \delta_{3}=\left(v\left(p_{1}\right)-t_{1}\left(\bar{V}+V_{1} \frac{\partial \bar{V} / \partial s_{1}}{\partial V_{1} / \partial s_{1}}\right)-A_{1} B\right) /(1+\lambda), \\
& \delta_{4}=\left(w\left(s_{1}\right)-V_{1} B+t_{2}\left(\bar{A}+A_{1} \frac{\partial \bar{A} / \partial s_{1}}{\partial A_{1} / \partial s_{1}}\right)\right) /(1+\lambda) .
\end{aligned}
$$

These terms reflect the change in the utility of viewers and advertisers due to changes in the prices of the services. Finally, using the expressions in Equation 19 and assuming that $\mu>0$ we obtain the prices of the proposition.

\section{Proof of Proposition 3}

Differentiating the Lagrangian with respect to the prices and rearranging we obtain:

$$
\begin{aligned}
& \left(V_{i} p_{i}-c_{i}-\frac{\mu}{1+\lambda_{i}}\right) \frac{\partial Q_{i}}{\partial p_{i}}+ \\
& \sum_{j=1}^{2} \frac{\partial V_{j}}{\partial p_{i}}\left[p_{j} Q_{j}+\frac{v\left(p_{j}\right)-\left(t_{1}\left(\bar{V}_{j}+V_{1} \frac{\partial \bar{V}_{j} / \partial p_{j}}{\partial V_{j} / \partial p_{j}}\right)-A_{1} B\right)}{1+\lambda}\right]+ \\
& \sum_{j=i}^{2} \frac{\partial A_{j}}{\partial p_{i}}\left[\left(s_{j}-b_{j}-\frac{\mu_{2}}{1+\lambda}\right) X_{j}+\frac{w\left(s_{j}\right)-\left(V_{j} B_{j}-t_{2}\left(\bar{A}_{j}+A_{j} \frac{\partial \bar{A}_{j} / \partial p_{j}}{\partial A_{j} / \partial p_{j}}\right)\right)}{1+\lambda}\right]+ \\
& (a-\beta) \frac{\partial \hat{K}_{e}}{\partial p_{i}}=-\theta V_{i} Q_{i}
\end{aligned}
$$


$A_{i}\left(s_{i}-b_{i}-\frac{\mu_{1}}{1+\lambda_{i}}\right) \frac{\partial X_{i}}{\partial s_{i}}+$
$\sum_{j=1}^{2} \frac{\partial V_{j}}{\partial s_{i}}\left[p_{j} Q_{j}+\frac{v\left(p_{j}\right)-\left(A_{j} B_{j}+t_{1}\left(\bar{V}_{j}+V_{j} \frac{\partial \bar{V}_{j} / \partial s_{j}}{\partial V_{j} / \partial s_{j}}\right)\right)}{1+\lambda}\right]-\sum_{j=1}^{2} \frac{V_{i} \alpha_{1} A_{i} \frac{\partial X_{i}}{\partial s_{i}}}{1+\lambda}+$

$\sum_{j=i}^{2} \frac{\partial A_{j}}{\partial s_{i}}\left[\left(s_{j}-b_{j}-\frac{\mu_{2}}{1+\lambda}\right) X_{j}+\frac{w\left(s_{j}\right)-\left(V_{j} B_{j}+t_{2}\left(\bar{A}_{j}+A_{j} \frac{\partial \bar{A}_{j} / \partial s_{j}}{\partial A_{j} / \partial s_{j}}\right)\right)}{1+\lambda}\right]+$

$(a-\beta) \frac{\partial \hat{K}_{e}}{\partial s_{i}}=-\theta X_{i}$

$\left(V_{2} p_{2}-c_{2}-\frac{\mu_{2}}{1+\lambda}\right) \frac{\partial Q_{i}}{\partial a}+G_{2}\left(s_{2}-b_{1}-\frac{\mu_{2}}{1+\lambda}\right) \frac{\partial X_{2}}{\partial a}+$

$\sum_{j=1}^{2} \frac{\partial V_{j}}{\partial a}\left[p_{j} Q_{j}+\frac{v\left(p_{j}\right)-\left(A_{j} B_{j}+t_{2}\left(\bar{V}_{j}+V_{j} \frac{\partial \bar{V}_{j} / \partial a}{\partial V_{j} / \partial a}\right)\right)}{1+\lambda}\right]+$

$\sum_{j=i}^{2} \frac{\partial A_{j}}{\partial a}\left[\left(s_{j}-b_{j}-\frac{\mu_{2}}{1+\lambda}\right) X_{j}+\frac{w\left(s_{j}\right)-\left(V_{j} B_{j}-t_{2}\left(\bar{A}_{j}+A_{j} \frac{\partial \bar{A}_{j} / \partial a}{\partial A_{j} / \partial a}\right)\right)}{1+\lambda}\right]+$

$\left(a-\frac{\mu_{2}}{1+\lambda}\right) \frac{\partial \hat{K}_{2}}{\partial a}=-\theta \hat{K}_{2}$,

where $B_{\mathrm{j}}=\alpha_{1} X_{\mathrm{j}}-\alpha_{2}$. Note that the first order conditions with respect to the retail prices reflect the effect of a change in the price of one service on the market share of the two services in the two channels. Finally, by rearranging Equation 31 and 
defining $M_{j}=t_{1}\left(\bar{V}_{j}+V_{j} \frac{\partial \bar{V}_{j} / \partial a}{\partial V_{j} / \partial a}\right)$ and $N_{j}=t_{2}\left(\bar{A}_{j}+A_{j} \frac{\partial \bar{A}_{j} / \partial a}{\partial A_{j} / \partial a}\right)$ we obtain the statement of the proposition. 